\title{
Preparation and Characterization of Chitosan/Bentonite Composites for Cr (VI) Removal from Aqueous Solutions
}

\author{
Junjie Jia, Yanjun Liu, and Shujuan Sun \\ College of Resources and Environment, Shandong Agricultural University, Taian, Shandong 271018, China \\ Correspondence should be addressed to Shujuan Sun; sunsjnk@sdau.edu.cn
}

Received 24 December 2020; Revised 21 August 2021; Accepted 26 August 2021; Published 22 September 2021

Academic Editor: Ming Hua

Copyright (c) 2021 Junjie Jia et al. This is an open access article distributed under the Creative Commons Attribution License, which permits unrestricted use, distribution, and reproduction in any medium, provided the original work is properly cited.

\begin{abstract}
Chitosan/bentonite composites (CSBT) prepared by physical gelation were tested for the adsorption of Cr (VI) from aqueous solutions in this work. The composites were prepared at a mass ratio from $2: 1$ to $1: 2$, and a composite of $1: 1$ was found to be most suitable for efficient Cr (VI) removal. The influencing parameters, including temperature, adsorbent dose, and $\mathrm{pH}$, were statistically optimized using response surface methodology (RSM) for the removal of Cr (VI). The $\mathrm{pH}$ was found to be the limiting factor during the adsorption process, and under the optimal conditions, namely, adsorbent dose of $400 \mathrm{mg} / \mathrm{L}, \mathrm{pH}$ $=3$, and temperature of $298 \mathrm{~K}, 87.61 \% \mathrm{Cr}$ (VI) would be removed expectantly. The mechanism of Cr (VI) removal by CSBT was discussed, and the protonation of amino groups on chitosan followed by the combination of $-\mathrm{NH}_{3}{ }^{+}$and anionic hexavalent chromium was the primary driving force. In addition, the removal of Cr (VI) onto CSBT was monolayer adsorption with a maximum adsorption capacity of $133.85 \mathrm{mg} / \mathrm{g}$ by the Langmuir isotherm. CSBT follows a pseudosecondorder kinetic model, and within $1.5 \mathrm{~h}$, adsorption was observed to reach equilibrium. The calculated thermodynamic functions clarified that the adsorption process was exothermic and spontaneous below $312.60 \mathrm{~K}$. CSBT could be regenerated after desorption by $0.5 \mathrm{~mol} / \mathrm{L} \mathrm{NaOH}$ solutions and exhibited superior reusability after six cycles. This study demonstrated composites of chitosan/bentonite as eco-friendly bioadsorbents for the removal of $\mathrm{Cr}$ (VI) from aqueous environments.
\end{abstract}

\section{Introduction}

Heavy metals are critical contaminants that are harmful or carcinogenic to human health and pose a hazardous threat to the ecological environment. Chromium is a heavy metal that is widely used in industry and has two valence states, $\mathrm{Cr}$ (III) and Cr (VI). Trivalent chromium is less toxic and considered to be an important element for plants and animals, as it has a high value for sugar and lipid metabolism $[1,2]$. Cr (VI) can cause arthritis and barrier disruption in contacts with the skin $[3,4]$ and nasal septum perforation in severe contact with the respiratory tract $[5,6]$. Large amounts of ingestion of $\mathrm{Cr}$ (VI) can cause liver enlargement, circulatory failure, and even death [7]. Almost all chromium ore is processed through hexavalent chromium, which is used in anticorrosion, metal protection, paints, and dyes, so industrial wastewater has become the main source of hexavalent chromium pollution [8-10]. Due to the high toxicity of $\mathrm{Cr}(\mathrm{VI})$, wastewater must be treated to reduce the harm of hexavalent chromium. Ion exchange, chemical precipitation, bioremediation, electrolysis, and membrane separation [11-15] are often used in heavy metal removal in aqueous environments. These treatment methods have limited applications because they are not effective for hexavalent chromium wastewater with a lower concentration of less than $100 \mathrm{mg} / \mathrm{L}$, and the treatment cost is too high. Adsorption is easy and inexpensive to remove heavy metals in wastewater effectively; thus, it may be superior to other chromium wastewater treatment methods [16-19].

Natural polymer materials have attracted increasing attention as adsorbents due to their biodegradability and lower toxicity [20]. Chitosan (Chi) is a polysaccharide obtained from the deacetylation of chitin, which has rich functional groups and is widely used as an adsorbent to remove heavy metal ions [21,22]. The large number of 
amino groups in Chi structure can be protonated in an acid solution and then adsorb anionic compounds [23]. The amino groups and hydroxyl groups of Chi allow various chemical or physical modifications to expand its applications. By hydrogen bonding, hydrophobic interaction, or covalent bonding, chitosan molecules can relate to each other to form physical or chemical gels [24-26]. However, chitosan physical hydrogels prepared by dissolving in acid solution and then sinking into alkali solutions always cause the degradation of chitosan macromolecule chains, leading to a decrease in the mechanical strength of chitosan hydrogels. To overcome this shortcoming, several methods have been used to enhance their mechanical strength, such as nanofiller reinforcement and blending with other polymers. To overcome this shortcoming, bentonite was introduced into chitosan. Bentonites have a layered structure with exchangeable cations between the space and have a certain dispersibility, chargeability, and hydration in aqueous solution. It is helpful to prepare mechanically stable enhanced physical crosslinking hydrogels by dropping chitosan/clay suspensions into sodium hydroxide solution. Huang et al. [27] prepared a chitosan composite hydrogel, and the viscosity of the composite solution increased with clay mineral content. The mechanical properties and antideformation ability of the composite hydrogel significantly increased owing to the reinforcing effect of clay minerals. The compressive strength of pure chitosan hydrogel was $0.14 \mathrm{MPa}$, and the compressive strength was significantly increased to $0.71 \mathrm{MPa}$ after adding clay minerals.

The intercalation and adsorption of chitosan on bentonite provide more adsorption sites for the composite, making the adsorption performance of the composite for heavy metals significantly better than montmorillonite [28]. These characteristics make the chitosan/bentonite composite a kind of heavy metal adsorption material with broad development prospects. Zhang et al. [29] combined chitosan and bentonite to prepare composite materials for Sc (III) removal. The results showed that the chitosan/bentonite composite had excellent adsorption performance, and the heavy metals could not only electrostatically complex with carboxyl and hydroxyl groups but also chelate with amino, azo, and pyridine groups. Cheng et al. [30] used chitosan to load iron-aluminium bimetallic particles onto bentonite and found that the iron-aluminium bimetal was surrounded by chitosan and bentonite, which can effectively solve the problem of secondary pollution of nanometal particles. Due to the excellent synergy between chitosan, bentonite, and bimetals, the removal effect of composite materials on inorganic salts is effectively improved compared with that of a single material.

The purpose of this study was to synthesize chitosan/bentonite composites to effectively remove hexavalent chromium from wastewater. The optimal preparation conditions were determined, and the conditions for removing hexavalent chromium were optimized by responsive surface methodology. To understand the removal mechanism, studies and comparisons of adsorption isotherms, adsorption thermodynamics, and kinetic models were performed. The reusability of composite materials has also been studied.

\section{Materials and Methods}

2.1. Preparation of Chitosan/Bentonite Composites (CSBT). Chitosan (DA $\geq 95 \%$ ) and bentonite (BT) were purchased from Shanghai Macklin Biochemical Co., Ltd., China. All analytical solutions were prepared by the utilization of deionized water.

A pillared process was needed to improve the interaction of bentonite with chitosan [30]. The preparation of $\mathrm{Fe} / \mathrm{Al}$ pillared bentonite was carried out following the treatment of bentonite by hydroxyl-Fe and hydroxyl-Al. Hydroxyl-Fe with a final $\mathrm{OH} / \mathrm{Fe}$ mole ratio of 2.0 pillared solution was prepared after 2 hours of mixing of ferric nitrate and sodium carbonate. A mixture of $0.5 \mathrm{~mol} / \mathrm{L}$ aluminium chloride and $1 \mathrm{~mol} / \mathrm{L}$ sodium carbonate was used to produce a hydroxylAl pillared solution with a final $\mathrm{OH} / \mathrm{Al}$ mole ratio of 2.4. These solutions were used after $24 \mathrm{~h}$ ageing at $333 \mathrm{~K}$. Under constant stirring, hydroxyl-Fe and hydroxyl-Al pillared solutions were added at a ratio of 0.05 to the bentonite suspension. The resulting suspension was then stirred for 2 hours at room temperature. Then, after being washed several times with distilled water, dried at $378 \mathrm{~K}$ and then ground, an $\mathrm{Fe}: \mathrm{Al}$ : bentonite ratio of $0.5: 10: 1$ pillared bentonite (AlBT) was obtained.

Chitosan was dissolved in acetic acid (2\%) with stirring overnight at room temperature $(298 \pm 2 \mathrm{~K})$. Then, a certain amount of pillared bentonite was added. After 2 hours of stirring, the suspension was poured into $0.5 \mathrm{~mol} / \mathrm{L} \mathrm{NaOH}$ to prepare the physical gel. Sufficient agitation was needed to prevent the product from sticking. Finally, the products were washed with distilled water to neutral $\mathrm{pH}$, dried at $333 \mathrm{~K}$, and ground to obtain the chitosan-bentonite composite.

2.2. Characterization of CSBT. Different analyses were conducted to characterize CSBT, such as Fourier transform infrared (FT-IR) spectroscopy, X-ray power diffraction (XRD), and scanning electron microscopy (SEM). Specifically, a D8 ADVANCE (Bruker, Germany) X-ray diffractometer was used to obtain XRD patterns with $\mathrm{Cu} / \mathrm{K} \alpha$ radiation wavelengths of $1.54056 \mathrm{~nm}$ and angles of $5^{\circ}-40^{\circ}$ at room temperature. A Fourier transform infrared spectrophotometer (Nicolet IS10) Thermo Nicolet, USA, was used to analyse functional groups with $400-4000 \mathrm{~cm}-1$ wavelength ranges of single beam optics. A HITACHI scanning electron microscope (SU8020), Japan, was used to analyse the surface morphology.

2.3. Selection of CSBT Based on Cr (VI) Removal. Various concentrations of $\mathrm{K}_{2} \mathrm{Cr}_{2} \mathrm{O}_{7}$ solutions were obtained by diluting the chromium standard solution $(1000 \mathrm{mg} / \mathrm{L}$, TMRM China).

CSBT synthesized at different chitosan/bentonite ratios was tested to select the best adsorbents with the maximum removal percentage. CSBT $(20 \mathrm{mg})$ was added to $50 \mathrm{~mL}$ of potassium dichromate, in which the $\mathrm{Cr}$ (VI) concentration was $10 \mathrm{mg} / \mathrm{L}$, in a $100 \mathrm{~mL}$ conical flask and agitated in a magnetic stirrer at $180 \mathrm{rpm}$ for $1.5 \mathrm{~h}$ at room temperature $(298 \pm 2 \mathrm{~K})$. Thereafter, the solutions were filtered, and the 
filtrates were analysed by a UV-vis spectrophotometer (Beijing Purkinje, China) to determine the concentration of Cr (VI) ions with the 1, 5-diphenyl carbazide method at $540 \mathrm{~nm}$. The sorption capacity and removal percentage were calculated with Equations (1) and (2), respectively. All experiments were performed in triplicate, and average values are reported.

$$
\begin{aligned}
& q_{e}=\frac{\left(C_{0}-C_{e}\right) \cdot V}{m}, \\
& R(\%)=\frac{C_{0}-C_{e}}{C_{0}},
\end{aligned}
$$

where $C_{0}$ is the initial $\mathrm{Cr}(\mathrm{VI})$ concentration $(\mathrm{mg} / \mathrm{L}), C_{e}$ is the $\mathrm{Cr}(\mathrm{VI})$ equilibrium concentration $(\mathrm{mg} / \mathrm{L}), V$ is the volume (L) of $\mathrm{Cr}(\mathrm{VI})$ solutions, and $m$ is the mass of CSBT.

2.4. Optimization of Cr (VI) Removal Process. Temperature, initial $\mathrm{pH}$, and adsorbent dose were the main factors affecting the removal efficiency of $\mathrm{Cr}$ (VI). Adsorption experiments were performed at different temperatures (288$318 \mathrm{~K}$ ), different initial $\mathrm{pH}$ values (ranging from 2.5 to 9), and different doses of adsorbent $(100-1000 \mathrm{mg} / \mathrm{L})$ to analyse the independent effect of these factors on $\mathrm{Cr}$ (VI) removal. $\mathrm{HCl}(0.1 \mathrm{~mol} / \mathrm{L})$ and $\mathrm{NaOH}(0.1 \mathrm{~mol} / \mathrm{L})$ were used to adjust the $\mathrm{pH}$ of the chromium solution.

A response surface methodology- (RSM-) based BoxBehnken design was used for further optimization of the $\mathrm{Cr}$ (VI) removal process. The variable input parameters used were as follows: temperature, 288-308 K; dose of CSBT, 200$600 \mathrm{mg} / \mathrm{L} ; \mathrm{pH}, 2.3-5.5$; and factor level codes, -1 (low), 0 (medium), and 1 (high). The three independent variables used for statistical calculations were designed as $X_{1}$ (temperature), $X_{2}$ (dose of CSBT), and $X_{3}(\mathrm{pH})$. The selected ranges and levels of the three variables are listed in Table 1. The results were analysed using a coefficient of determination $\left(R^{2}\right)$ to investigate the model fitness, and the significance of each independent variable was determined using Fisher's test for analysis of variance (ANOVA) at $P<0.05$. A threedimensional response surface map was drawn to identify interactions or multifactor effects between response factors.

2.5. Adsorption Isotherm. Adsorption isotherm experiments were carried out at 288, 298, and $308 \mathrm{~K}$, a $\mathrm{pH}$ of 3 , and $20 \mathrm{mg}$ of adsorbent, and the initial concentrations of $\mathrm{Cr}$ (VI) ranged from 5-500 $\mathrm{mg} / \mathrm{L}$. The experimental data were analysed with Langmuir, Freundlich, Temkin, and Dubinin-Radushkevich (D-R) isotherm models (Equations (3) and (4)).

$$
\begin{aligned}
\frac{C_{e}}{Q_{e}} & =\frac{1}{Q_{m} \cdot K_{L}}+\frac{C_{e}}{Q_{m}}, \\
\ln Q_{e} & =\ln K_{F}+\frac{1}{n} \ln C_{e}, \\
Q_{e} & =B \ln A+B \ln A, \\
\ln Q_{e} & =\ln Q_{e}-b \cdot \Sigma^{2},
\end{aligned}
$$

TABLE 1: Factors and values of Box-Behnken design.

\begin{tabular}{ccccc}
\hline & & Temperature $(\mathrm{K})$ & Adsorbent dose $(\mathrm{mg} / \mathrm{L})$ & $\mathrm{pH}$ \\
\hline$X_{1}$ & -1 & 288 & 200 & 2.5 \\
$X_{2}$ & 0 & 298 & 400 & 3 \\
$X_{3}$ & 1 & 308 & 600 & 3.5 \\
\hline
\end{tabular}

TABLE 2: Removal percentages of different CS/BT ratios.

\begin{tabular}{cccc}
\hline$\#$ & Ratio of chi mass & Ratio of BT mass & Removal percentage (\%) \\
\hline 1 & $2 \%$ & $1 \%$ & $80.07 \%$ \\
2 & $1 \%$ & $1 \%$ & $88.84 \%$ \\
3 & $0.5 \%$ & $1 \%$ & $86.68 \%$ \\
4 & $1 \%$ & $2 \%$ & $81.74 \%$ \\
5 & $1 \%$ & $0.5 \%$ & $72.71 \%$ \\
\hline
\end{tabular}

where $C_{e}$ is the equilibrium $\mathrm{Cr}(\mathrm{VI})$ concentration $(\mathrm{mg} / \mathrm{L})$, $Q_{e}$ is the equilibrium adsorption capacity $(\mathrm{mg} / \mathrm{g}), Q_{m}$ is the maximum adsorption capacity of CSBT, $K_{L}$ is the Langmuir affinity constant $(\mathrm{L} / \mathrm{mg}), K_{F}$ is the Freundlich constant $(\mathrm{mg} / \mathrm{g})$ relating to the adsorption affinity, $n$ is the Freundlich equation exponent relating to the heterogeneity of the adsorbent surface, $A$ and $B$ are Temkin constants, $b$ is the adsorption energy, and $\Sigma$ is the Polanyi potential energy.

2.6. Adsorption Kinetics. After different agitation times, the removal percentage of $\mathrm{Cr}$ (VI) by CSBT was measured, and pseudofirst-order and pseudosecond-order kinetic models (Equations (5) and (6)) were fitted to investigate the adsorption mechanism.

$$
\begin{gathered}
\ln \left(Q_{e}-Q_{t}\right)=\ln Q_{e}-K_{1} \cdot t, \\
\frac{t}{Q_{t}}=\frac{1}{K_{2} \cdot Q_{e}^{2}}+\frac{t}{Q_{e}},
\end{gathered}
$$

where $Q_{t}$ is the adsorption capacity at time $t(\mathrm{mg} / \mathrm{g})$, and $k_{1}$ $\left(\mathrm{min}^{-1}\right)$ and $k_{2}\left(\mathrm{mg}^{-1} \cdot \mathrm{min}^{-1}\right)$ are the rate constants of firstand second-order kinetics, respectively.

2.7. Reusability of CSBT. $\mathrm{NaOH}(0.1 \mathrm{~mol} / \mathrm{L})$ was used to desorb the $\mathrm{Cr}$ (VI) adsorbed. $\mathrm{NaOH}(50 \mathrm{~mL})$ was added to the adsorbents in a $100 \mathrm{~mL}$ conical flask and agitated in a magnetic stirrer at $180 \mathrm{rpm}$ for $1.5 \mathrm{~h}$ at room temperature $(298 \pm 2 \mathrm{~K})$ to desorb the adsorbed Cr (VI). After desorption, the CSBT was reused to adsorb Cr (VI) again. The desorption $\mathrm{Cr}(\mathrm{VI})$ concentration and readsorbed $\mathrm{Cr}$ (VI) concentration were analysed to investigate the reusability of CSBT.

\section{Results and Discussions}

3.1. Effect of Different Chitosan/Bentonite Ratios on Cr (VI) Removal. By fixing the mass of chitosan or AlBT and changing the mass of the other, the effect of different mass ratios on $\mathrm{Cr}$ (VI) removal was studied, and the results are shown in Table 2. When the mass ratio of both chitosan and AlBT 


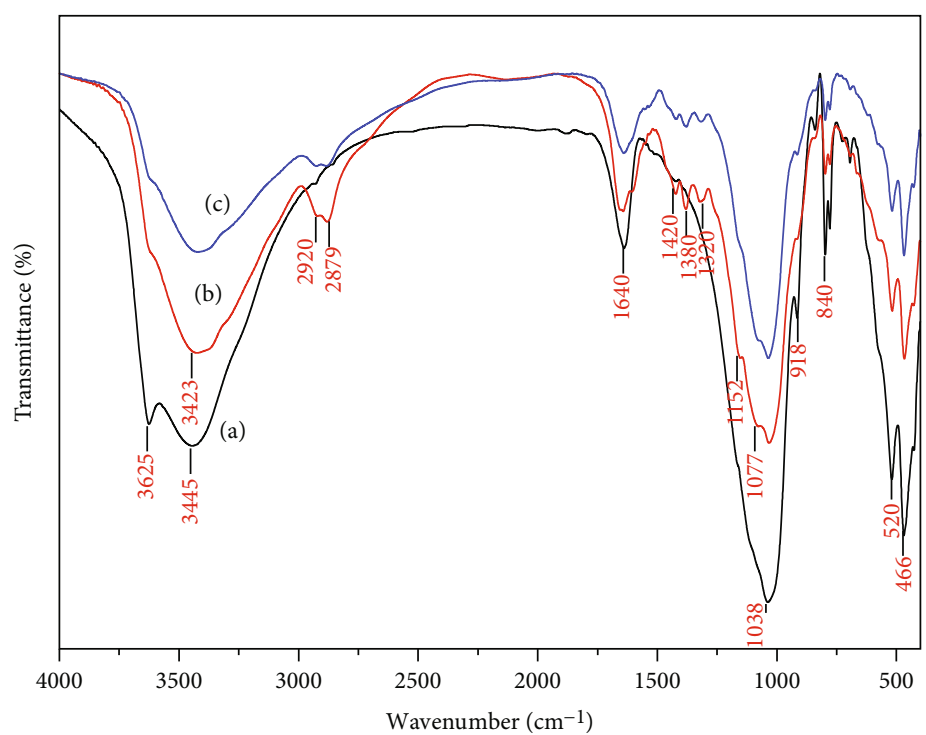

Figure 1: FTIR spectra of AlBT (a), CSBT (b), and CSBT after Cr (VI) removal (c).

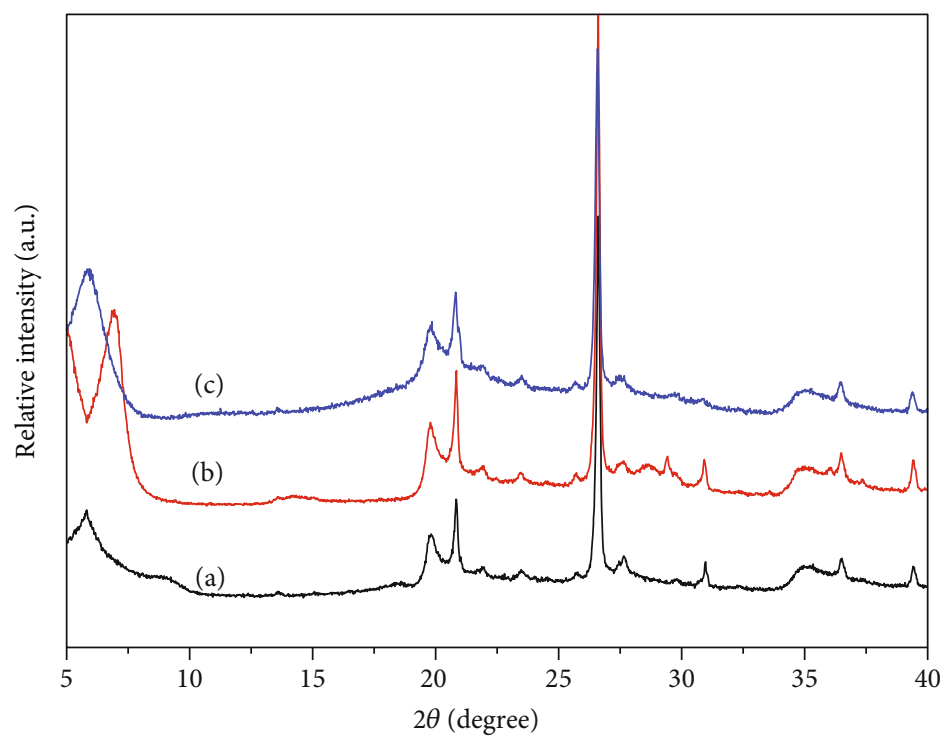

Figure 2: X-ray diffusion spectra of bentonite (a), AlBT (b), and CSBT (c).

was $1 \%$, the adsorption removal of $\mathrm{Cr}$ (VI) was the most effective. The higher the proportion of chitosan was, the larger and harder the beads formed in the sodium hydroxide solution, and the volume shrank and led to the collapse of the structure after drying due to surface tension [31]. If the proportion was lower than $1 \%$, the $\mathrm{NaOH}$ solution hindered the gelation process by diluting the chitosan solution and led to the formation of a precipitate [32]. The number of amino and hydroxyl groups as sorption sites would decrease, and the adsorption efficiency would decrease as well. Taking these factors into account, the adsorption efficiency was the best when both the mass ratio of chitosan and bentonite were $1 \%$, and it was suitable as a Cr (VI) adsorbent. Next, the adsorption performance of CSBT with a mass ratio of chitosan and bentonite of $1 \%$ for Cr (VI) was systematically studied.

\subsection{Characterization of CSBT}

3.2.1. Fourier Transform Infrared (FTIR) Spectroscopy. The FTIR spectra of AlBT, CSBT, and ACSBT are shown in Figure 1. The characteristic absorption band of bentonite at $1038 \mathrm{~cm}^{-1}$ (asymmetrical bond stretching vibration of Si$\mathrm{O}-\mathrm{Si}$ ) appeared in the curve of CSBT [33], indicating that the silicate layer structure of bentonite was not destroyed after the reaction of chitosan and AlBT. In CSBT, the absorption bands at $3625 \mathrm{~cm}^{-1}$ (hydrogen stretching vibration peak) in the curve of AlBT disappeared, the other hydroxyl-related absorption bands $\left(3445 \mathrm{~cm}^{-1}\right.$ of interlayer hydroxyl stretching vibration peak [34], $918 \mathrm{~cm}^{-1}$ of $\mathrm{Al}-\mathrm{OH}$ bending vibration peak, and $840 \mathrm{~cm}^{-1}$ of $\mathrm{Al}-\mathrm{Mg}-\mathrm{OH}$ bending vibration peak) were also attenuated or shifted, and the characteristic absorption band of chitosan corresponding to $\mathrm{NH}_{2}$ 


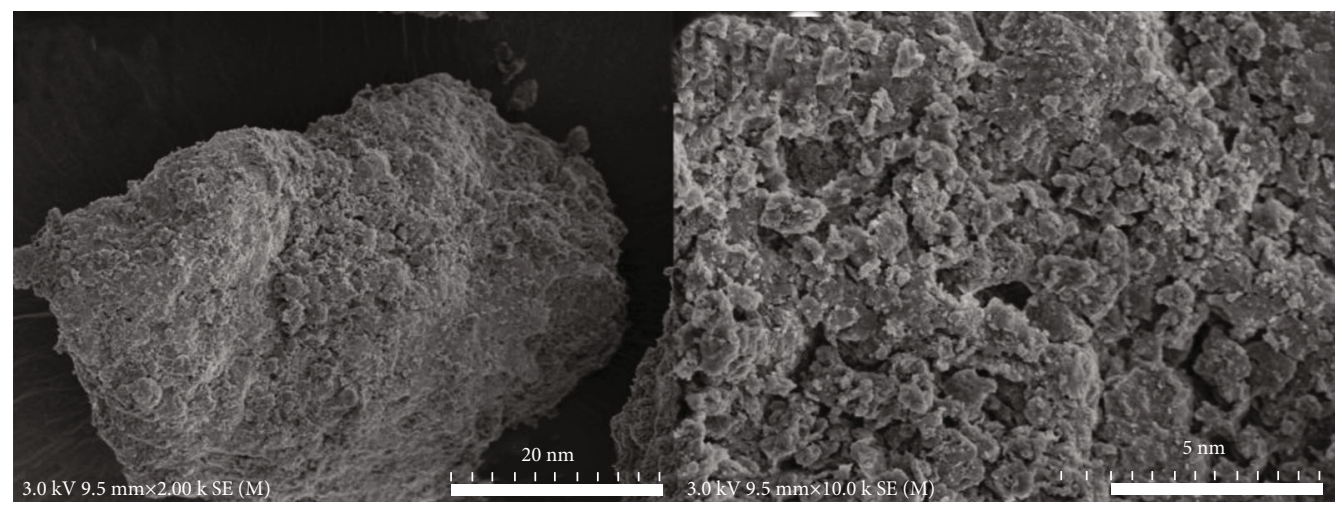

(a)

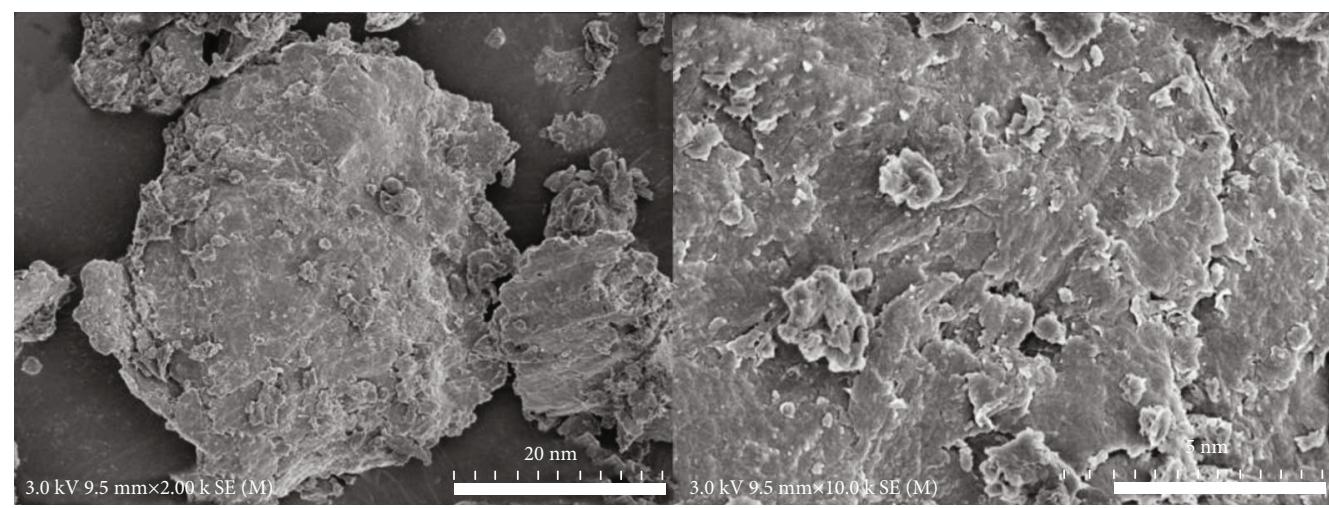

(b)

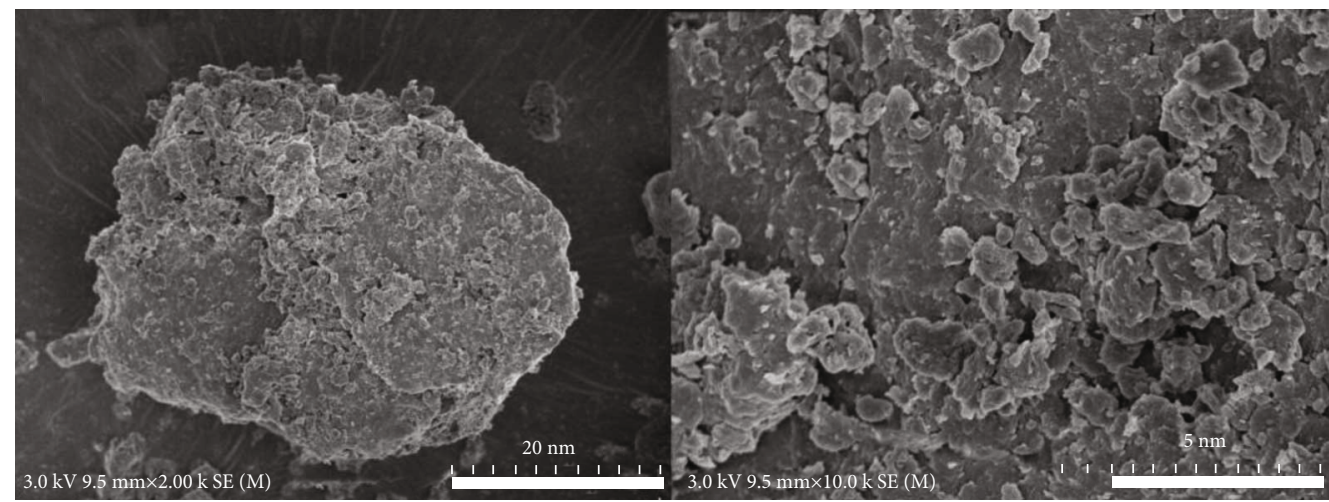

(c)

Figure 3: SEM images of AlBT (a), CSBT (b), and CSBT after Cr (VI) removal (c).

vibration at $1601 \mathrm{~cm}^{-1}$ disappeared [35], which shows that the hydroxyl groups on bentonite reacted with amino groups on chitosan.

After Cr (VI) adsorption, the characteristic bands at $3445,1640,1420,1152$, and $1038 \mathrm{~cm}^{-1}$, which are related to $\mathrm{NH}$ vibrations, $\mathrm{CN}$ stretching, and $\mathrm{OH}$ vibrations, were attenuated [36]. These results agreed with former reports that $-\mathrm{NH}_{2}$ groups are the main reaction sites adsorbing hexavalent chromium [37].

3.2.2. X-Ray Diffraction (XRD) Spectra. XRD spectra of BT, $\mathrm{AlBT}$, and CSBT were given in Figure 2. The XRD results revealed that the main composites of $\mathrm{BT}$, AlBT, and CSBT are montmorillonite. Compared with bentonite, no new dif- fraction peak is added after pillaring. The only changes appeared at the $d(001)$ spacing, indicating that the pillar process only had a significant effect on the $d(001)$ spacing. The value of the $d(001)$ spacing increased from $1.271 \mathrm{~nm}$ for the original bentonite to over $1.759 \mathrm{~nm}$ for AlBT. After combining with chitosan, the excessive interlayer distance of pillared bentonite decreased, and the value of d001 dropped to $1.488 \mathrm{~nm}$, which may be due to the formation of hydrogen bonds between chitosan and bentonite interlayer hydroxyl groups, confirming the synthesis of chitosan/bentonite composites.

3.2.3. Scanning Electron Microscopy. As shown in Figure 3, the pillared bentonite montmorillonite particles maintained 
a layered structure, but the surface split, forming many small layered particles, which were aggregated with each other forming irregular pores. After the addition of chitosan, the cluster property of the pillared bentonite was improved, the particles became larger, the surface became smooth, and the edges were more obvious, indicating that part of the chitosan was successfully inserted between the layers. After adsorbing Cr (VI), from a macroscopic perspective, the colour of CSBT was yellow-green, which is the colour of $\mathrm{Cr}$ (VI). After drying, the colour of CSBT was similar to that of soil, and the texture became loose. Corresponding to the SEM image, the number of surface particles increased, and the composites split again.

During the adsorption process, the amino groups were protonated by hydrogen ions in acidic solutions following the breakage of hydrogen bonds between amino and hydroxyl groups, which weakened the combination of chitosan and the bentonite silicate layer. Then, hexavalent chromium ions entered the interlayer and combined with $-\mathrm{NH}_{3}{ }^{+}$, so the silicate layer split again, resulting in a decrease in the cluster property of CSBT after drying.

3.3. Optimization of Cr (VI) Removal Process. To investigate the optimal Cr (VI) removal conditions, 17 runs for a threeparameter Box-Behnken experimental design were performed. The experimental data are given in Table 3, and a polynomial equation was determined for the removal percentage.

$$
\begin{aligned}
Y= & 87.61-4.95 X_{1}+8.66 X_{2}+12.46 X_{3}+0.74 X_{1} X_{2} \\
& -1.15 X_{1} X_{3}+0.40 X_{2} X_{3}-0.73 X_{1}^{2}-6.77 X_{2}^{2} \\
& -35.64 X_{3}^{2} .
\end{aligned}
$$

In Equation (8), a negative value indicates that this factor has an antagonistic effect, and a positive value indicates that there is a synergistic effect [38]. The value of adsorbent dose and $\mathrm{pH}$ is positive, indicating that increasing these values contributes to increasing removal percentages. The negative value of temperature indicates that the temperature increment is not conducive to the improvement of the removal percentage.

The $F$ value and $P$ value of ANOVA can evaluate the significance of influencing factors. The larger the $F$ value and smaller the $P$ value are, the more reliable the experimental data. In this experiment, the $F$ value was 108.04 , and the $P$ value was less than 0.0001 , indicating that the experimental data were reliable (Table 4). In addition, the $P$ value of $X_{1}$, $X_{2}, X_{3}, X_{2}{ }^{2}$, and $X_{3}{ }^{2}$ are less than 0.05 , which means that the influence of these factors cannot be ignored, and the interactive effect of any two factors is not significant on removal percentage [39]. The $P$ value of "lack of fit" is 0.0525 , and the correlation coefficient is 0.9929 , revealing that the predictability of this model is reliable.

According to ANOVA, the effect of temperature and adsorbent dose on Cr (VI) removal by CSBT is significant. The corresponding three-dimensional response surface map of the removal percentage for these two factors is shown in Figure 4. In the experimental temperature range,
TABLE 3: Experimental design and its actual values.

\begin{tabular}{lcccc}
\hline$\#$ & Temperature & $\begin{array}{c}\text { Adsorbent dose } \\
\mathrm{pH}_{2}\end{array}$ & $\begin{array}{c}\text { Removal } \\
\text { percentage (\%) }\end{array}$ \\
\hline 1 & $X_{1}$ & 0 & 1 & 57.1 \\
2 & 1 & 0 & 1 & 70.96 \\
3 & -1 & 0 & -1 & 33.83 \\
4 & 1 & -1 & -1 & 27.06 \\
5 & 0 & 1 & 1 & 64.16 \\
6 & 0 & -1 & 1 & 50.5 \\
7 & 0 & 0 & 0 & 87.43 \\
8 & 0 & 1 & 0 & 87.62 \\
9 & 1 & 0 & 0 & 88.31 \\
10 & 0 & 0 & 0 & 86.08 \\
11 & 0 & 0 & 0 & 89.89 \\
12 & 0 & 1 & 0 & 94.39 \\
13 & -1 & 0 & 0 & 86.36 \\
14 & 0 & 0 & -1 & 43.07 \\
15 & -1 & -1 & 0 & 64.36 \\
16 & 1 & 1 & -1 & 39.11 \\
17 & 0 & -1 & 0 & 74.09 \\
\hline
\end{tabular}

(Initial concentration, $10 \mathrm{mg} / \mathrm{L}$; contact time, $90 \mathrm{~min}$; rpm, 180).

the response surface increased significantly with increasing dose, and a high removal rate was always maintained in the high dose area $(400 \sim 600 \mathrm{mg} / \mathrm{g})$, which was not affected by the temperature. Compared with the influence of the dose, the change in the response surface is not obviously affected by the temperature. If the temperature is constant, the removal percentage increases with increasing adsorbent dose, which is attributed to the increase in the number of $-\mathrm{NH}_{2}$, and there are more sites reacting with $\mathrm{Cr}$ (VI). However, when the adsorbent dose is constant, an increase in temperature will cause a decrease in the removal percentage.

According to the above data, the optimal conditions for removing $\mathrm{Cr}(\mathrm{VI})$ are $\mathrm{pH}=3$, temperature $298 \mathrm{~K}$, and adsorbent dose of $400 \mathrm{mg} / \mathrm{L}$. The predicted removal percentage is $87.61 \%$, which is near agreement with the experimental maximum of $88.31 \%$.

\subsection{Effects of Influence Parameters on Cr (VI) Removal and Adsorption Capacity}

3.4.1. $p H$. The $\mathrm{pH}$ value of potassium dichromate solution is one of the important factors affecting the adsorption process. Therefore, the influence of $\mathrm{pH}$ values ranging from 2.5 to 9.0 on the adsorption capacity of CSBT to Cr (VI) was studied. The adsorption capacity of AlBT was lower than that of CSBT, as shown in Figure 5. AlBT lacks the abundant functional groups in chitosan and mainly absorbs heavy metal cations in solution by cation exchange. Compared with CSBT, it has a weak ability to adsorb anionic $\mathrm{Cr}$ (VI). In contrast, the maximum adsorption capacity of CSBT appeared at $\mathrm{pH}=3(22.10 \mathrm{mg} / \mathrm{g})$. When the $\mathrm{pH}$ value was greater than 3 , the adsorption capacity began to decrease until it reached $0.12 \mathrm{mg} / \mathrm{g}$ at $\mathrm{pH}=9.0$. In ANOVA, $\mathrm{pH}$ had a significant linear and quadratic effect $(P<0.0001)$ on the 
TABLE 4: ANOVA of responsive surface design.

\begin{tabular}{lccccc}
\hline Source & Sum of squares & df & Mean square & $F$ value & $P$ value Prob $>$ F \\
\hline Model & 7749.45 & 9 & 861.05 & 108.04 & $<0.0001$ \\
$X_{1}$ & 196.02 & 1 & 196.02 & 24.60 & 0.0016 \\
$X_{2}$ & 599.79 & 1 & 599.79 & 75.26 & $<0.0001$ \\
$X_{3}$ & 1241.27 & 1 & 1241.27 & 155.75 & $<0.0001$ \\
$X_{1} X_{2}$ & 2.19 & 1 & 2.19 & 0.27 & 0.6163 \\
$X_{1} X_{3}$ & 5.34 & 1 & 5.34 & 0.67 & 0.4402 \\
$X_{2} X_{3}$ & 0.65 & 1 & 0.65 & 0.081 & 0.7838 \\
$X_{1}{ }^{2}$ & 2.26 & 1 & 2.26 & 0.28 & 0.6106 \\
$X_{2}{ }^{2}$ & 192.74 & 1 & 192.74 & 24.18 & 0.0017 \\
$X_{3}{ }^{2}$ & 5348.48 & 1 & 5348.48 & 671.10 & $<0.0001$ \\
Residual & 55.79 & 7 & 7.97 & & 0.0525 \\
Lack of fit & 46.16 & 3 & 15.39 & 6.40 & Not significant \\
Pure error & 9.62 & 4 & 2.41 & & \\
Cor total & 7805.24 & 16 & & & \\
\hline
\end{tabular}

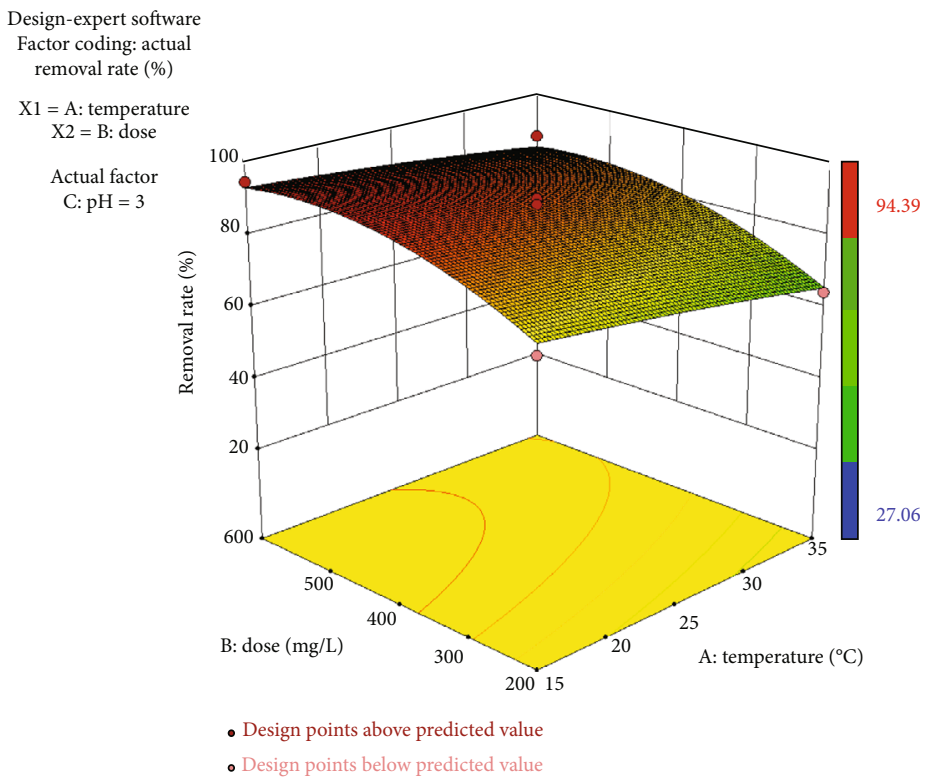

FIgURE 4: Responsive surface map of removal percentage for temperature and adsorbent dose.

removal percentage, meaning that $\mathrm{pH}$ was the limiting factor during $\mathrm{Cr}(\mathrm{VI})$ adsorption.

In the potassium dichromate solution, the existence form of $\mathrm{Cr}(\mathrm{VI})$ and the content of each form change with the change in $\mathrm{pH}$ value. At $\mathrm{pH}=2.5-5$, the main morphology is $\mathrm{HCrO}_{4}^{-}$. In an acidic solution, $-\mathrm{NH}_{2}$ in CSBT is protonated, and the positive charge is expected to combine with $\mathrm{HCrO}_{4}^{-}$by electrostatic attraction. In addition, the ligand-exchange mechanism chelating with $\mathrm{Fe}$ (III) could be another driving force in $\mathrm{Cr}$ (VI) adsorption because of the presence of hydroxyl-Fe [40]. When the $\mathrm{pH}$ value was 2.5 , part of the CSBT in the solution was dissolved, affect- ing the adsorption process. When the $\mathrm{pH}$ was greater than 3 , the solubility was not affected. Similar results have been reported in the literature. High-acidity solutions will increase the solubility of chitosan [41]. In solutions with a high initial concentration of molybdate, the removal effect was best at $\mathrm{pH}=3.5$, and at $\mathrm{pH} 5$ or 6 , the removal percentage was minimal. At near-neutral $\mathrm{pH}$, the electrostatic balance between anionic and cationic groups on the polymer would be expected to be less favourable for Cr (VI) binding. As the $\mathrm{pH}$ increases, the increased hydroxide will also compete with $\mathrm{Cr}$ (VI) for adsorption, reducing the adsorption capacity [42]. When the solution is alkaline or the $\mathrm{pH}$ 


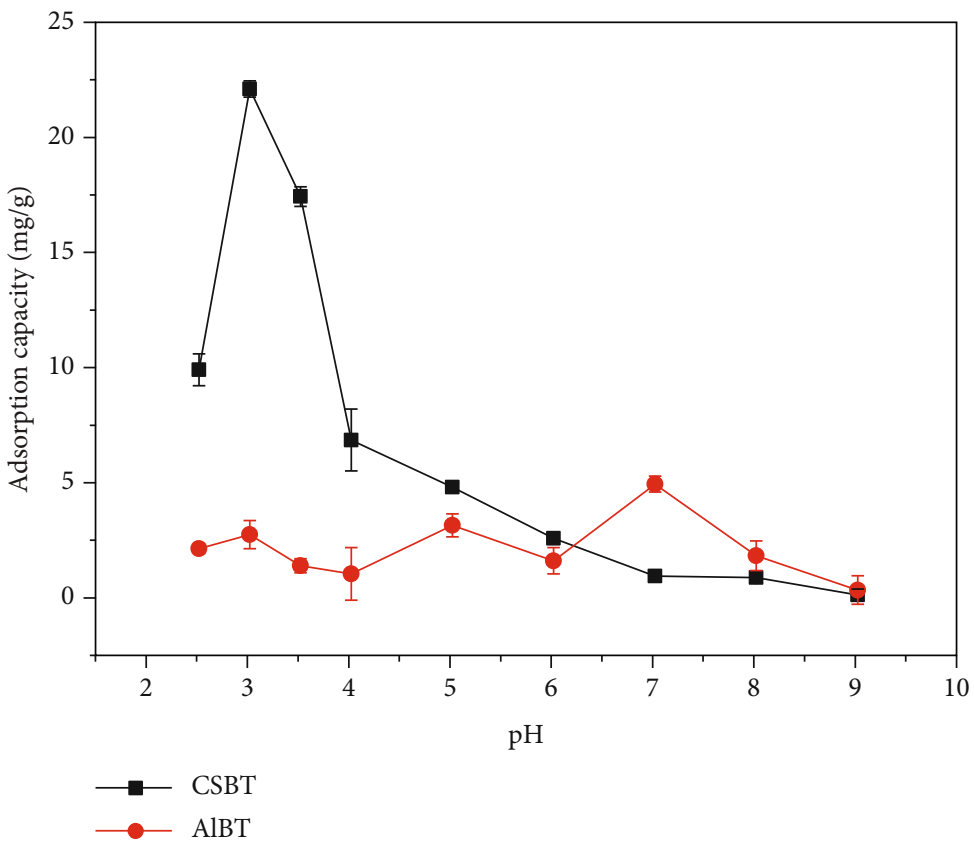

Figure 5: Effect of pH of Cr (VI) solutions on Cr (VI) removal by CSBT and AlBT. (absorbent dosaging, $400 \mathrm{mg} / \mathrm{L}$; initial concentration, $10 \mathrm{mg} / \mathrm{L}$; temperature, $298 \mathrm{~K}$; contact time, $90 \mathrm{~min}$; rpm, 180).

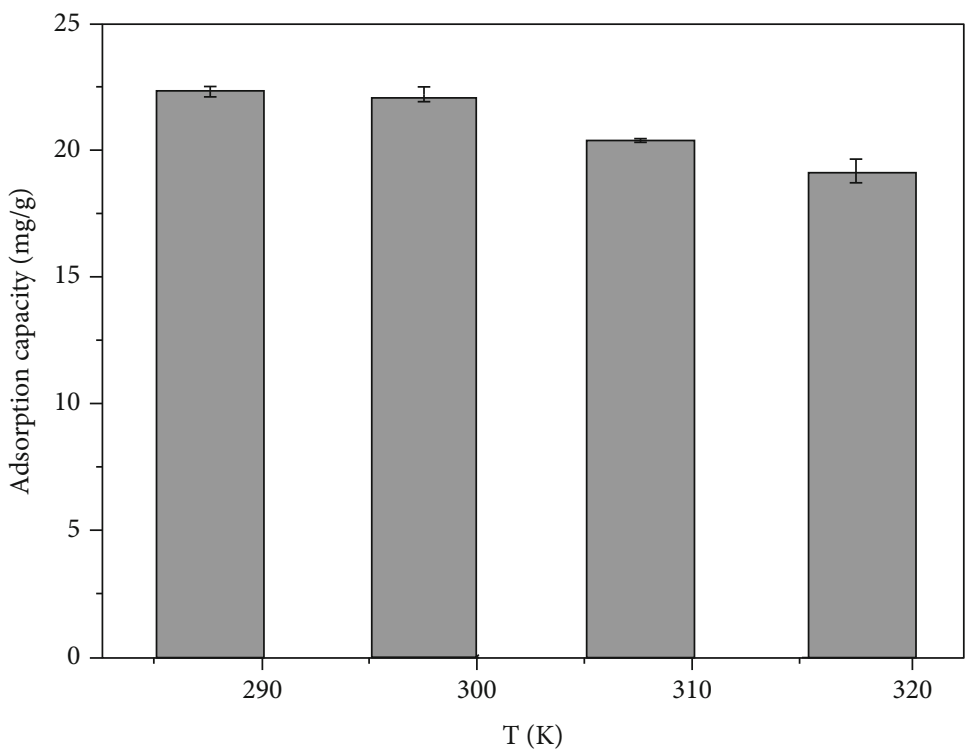

Figure 6: Effect of temperature on Cr (VI) removal of CSBT. (Absorbent dosaging, $400 \mathrm{mg} / \mathrm{L}$; initial concentration, $10 \mathrm{mg} / \mathrm{L}$; $\mathrm{pH}$ value, 3.0; contact time, 90 min; rpm, 180).

gradually increases, it will inhibit electrostatic adsorption, resulting in a low removal rate. Based on the above factors, to ensure the best adsorption of $\mathrm{Cr}(\mathrm{VI})$, the subsequent test $\mathrm{pH}$ was 3 .

3.4.2. Temperature and Thermodynamics. Temperature is another important factor affecting the adsorption process. In this experiment, temperature had a significant negative effect on the $\mathrm{Cr}(\mathrm{VI})$ removal percentage $(P=0.0016)$. With increasing temperature, the removal percentage decreased (Figure 6). Adsorption can be divided into physical adsorp- tion and chemical adsorption. Physical adsorption is fast, easily reaches equilibrium, and no activation energy is needed. Chemical adsorption is slow, has difficulty reaching equilibrium, and requires activation energy. The adsorption of Cr (VI) by CSBT was fast, and $63.51 \%$ of Cr (VI) was adsorbed within 5 minutes, indicating that at low temperature, the adsorption was physical. Since adsorption is exothermic, the adsorption capacity decreases with increasing temperature.

As most of the adsorption is performed at a lower temperature, adsorption thermodynamics were studied with 


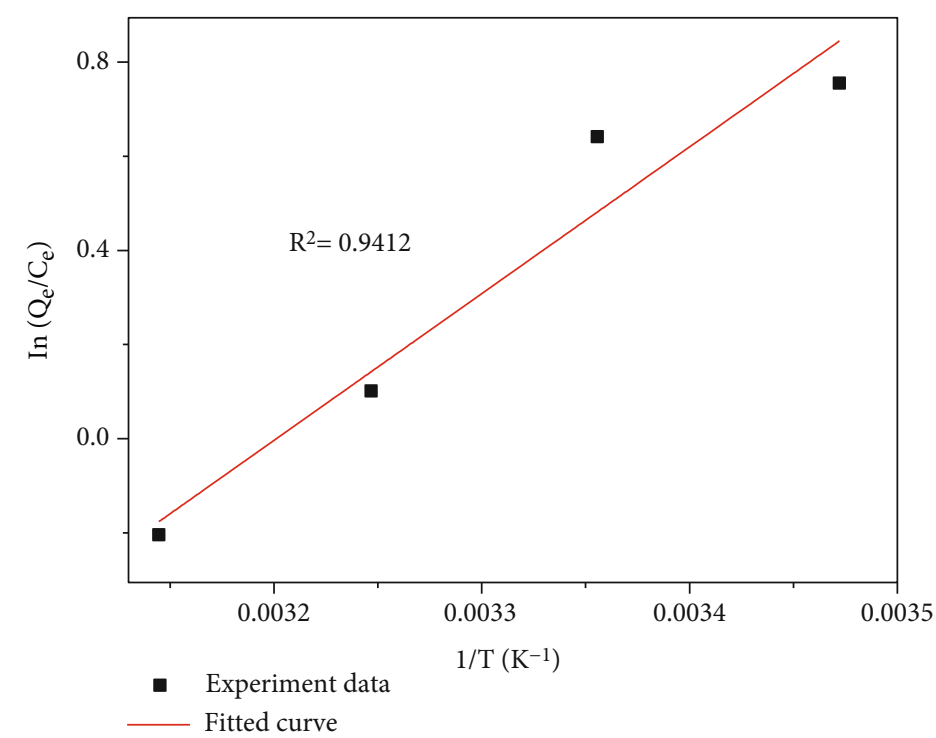

Figure 7: Thermodynamic adsorption for Cr (VI) removal on CSBT.

TABLE 5: Constants of adsorption thermodynamics for Cr (VI) of CSBT.

\begin{tabular}{lccccc}
\hline $\begin{array}{l}\Delta H \\
\left(\mathrm{~kJ} \cdot \mathrm{mol}^{-1}\right)\end{array}$ & $\begin{array}{c}\Delta S \\
\left(\mathrm{~J} \cdot \mathrm{mol}^{-1} \cdot \mathrm{K}^{-1}\right)\end{array}$ & $\begin{array}{c}\Delta G_{288 \mathrm{~K}} \\
\left(\mathrm{~kJ} \cdot \mathrm{mol}^{-1}\right)\end{array}$ & $\begin{array}{c}\Delta G_{298 \mathrm{~K}} \\
\left(\mathrm{~kJ} \cdot \mathrm{mol}^{-1}\right)\end{array}$ & $\begin{array}{c}\Delta G_{308 \mathrm{~K}} \\
\left(\mathrm{~kJ} \cdot \mathrm{mol}^{-1}\right)\end{array}$ & $\begin{array}{c}\Delta G_{318 \mathrm{~K}} \\
\left(\mathrm{~kJ} \cdot \mathrm{mol}^{-1}\right)\end{array}$ \\
\hline-25.93 & -82.95 & -2.04 & -1.21 & -0.38 & 0.45 \\
\hline
\end{tabular}

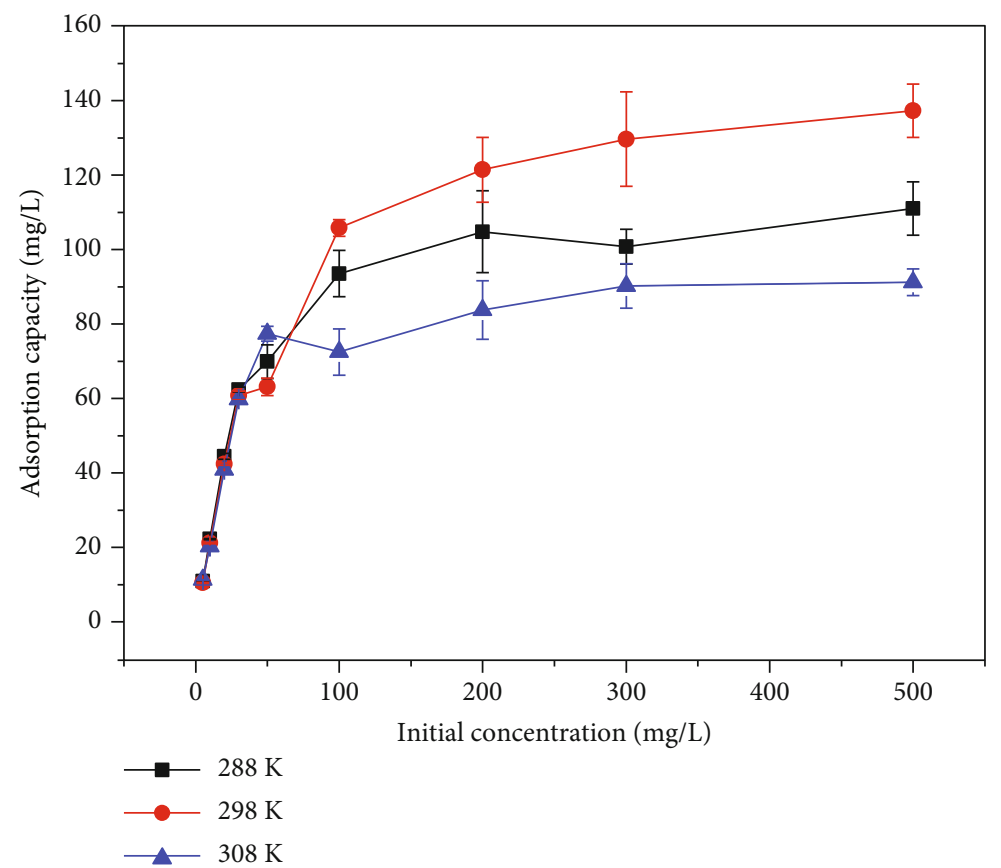

Figure 8: Effect of initial concentration of CSBT on Cr (VI) removal. (Absorbent dosaging, $400 \mathrm{mg} / \mathrm{L}$; $\mathrm{pH}$ value, 3.0; contact time, $90 \mathrm{~min}$; rpm, 180). 


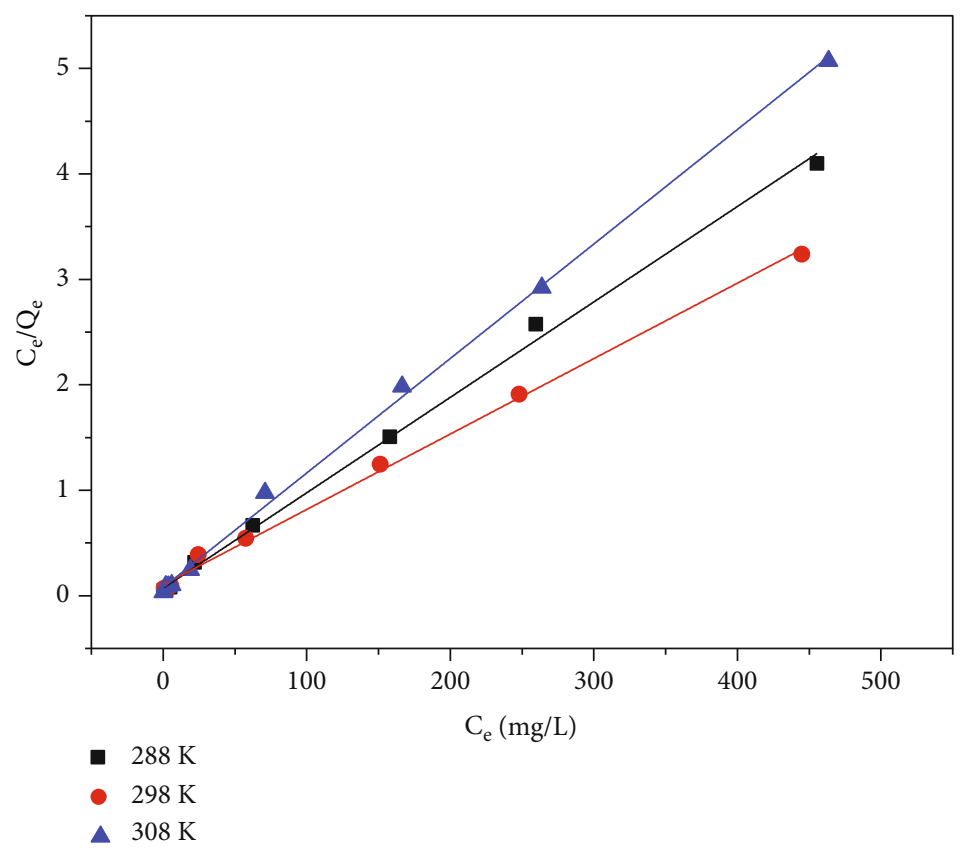

Figure 9: Langmuir isotherm for Cr (VI) removal on CSBT.

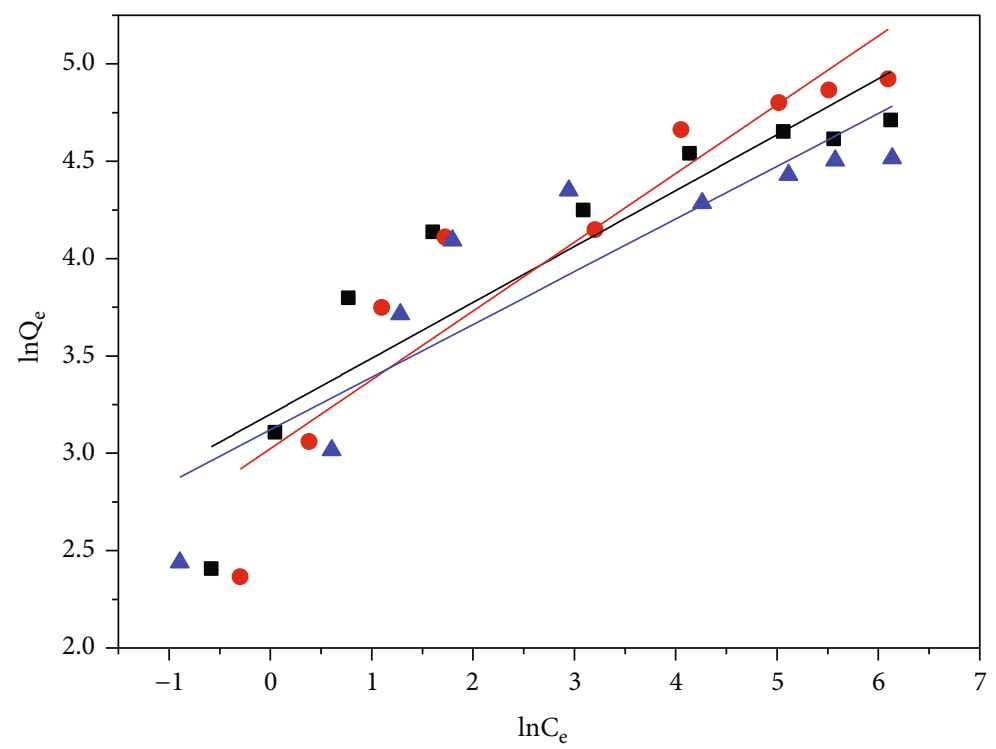

- $288 \mathrm{~K}$

- $298 \mathrm{~K}$

- $308 \mathrm{~K}$

FIgURE 10: Freundlich isotherm for Cr (VI) removal on CSBT.

the data at four temperatures of $288,298,308$, and $318 \mathrm{~K}$. To obtain thermodynamic parameter information, the experimental data were analysed using the van't Hoff equation (Equation (10)).

$$
\begin{gathered}
\ln \left(\frac{Q_{e}}{C_{e}}\right)=\frac{\Delta S}{R}-\frac{\Delta H}{R T}, \\
\Delta G=\Delta H-T \Delta S,
\end{gathered}
$$

where $\Delta S\left(\mathrm{~J} \cdot \mathrm{mol}^{-1} \cdot \mathrm{K}^{-1}\right)$ is the entropy change, $R\left(8.314 \mathrm{~J} \cdot \mathrm{mol}^{-}\right.$ $\left.{ }^{1} \cdot \mathrm{K}^{-1}\right)$ is the ideal gas constant, $\Delta H\left(\mathrm{~kJ} \cdot \mathrm{mol}^{-1}\right)$ is the enthalpy change, and $T(K)$ is the absolute temperature. To examine the spontaneity of the adsorption process, Equation (11) is used to calculate the Gibbs free energy.

As shown in Figure 7, the correlation coefficient $\left(R^{2}\right)$ is 0.9412 , meaning that the experimental data fit the equation well. The negative value of $\Delta H$ indicated that the adsorption was exothermic (Table 5). The negative value of $\Delta S$ revealed the decrement of randomness at the solid-solution interface, 


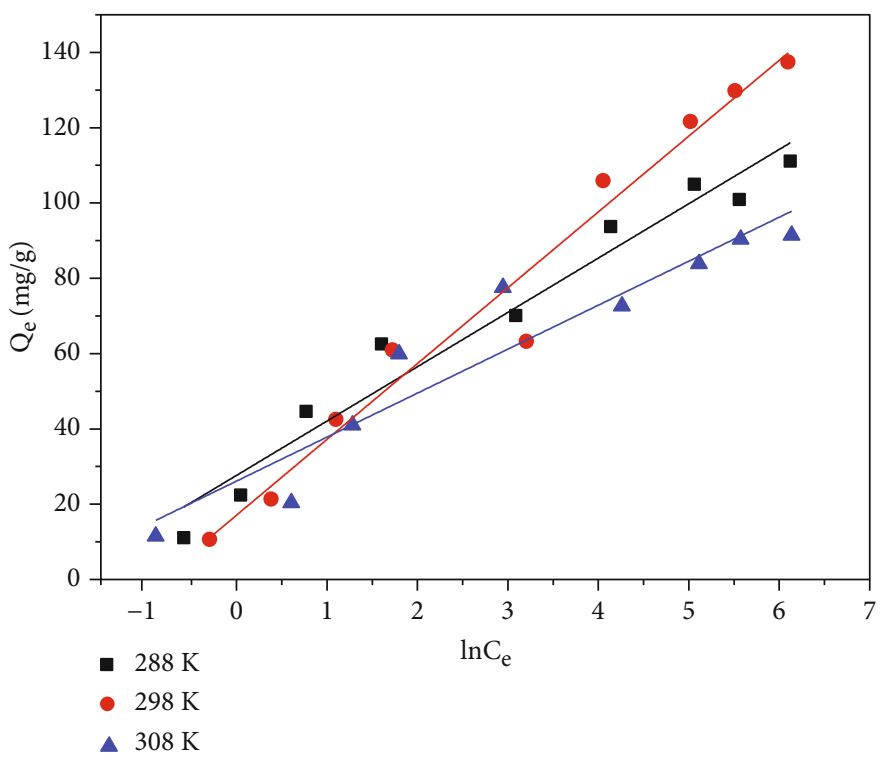

FIgURE 11: Temkin isotherm for Cr (VI) removal on CSBT.

meaning that CSBT has a better affinity towards hexavalent chromium [43]. Moreover, $\Delta G$ was negative at a lower temperature, and the adsorption process could be carried out spontaneously and was dominated by physical adsorption. However, with increasing temperature, specifically higher than $312.60 \mathrm{~K}, \Delta G$ becomes positive, and external energy is required to force the adsorption process to carry on.

3.4.3. CSBT Dose. With increasing CSBT dose, the removal efficiency of $\mathrm{Cr}$ (VI) increased. The maximum removal percentage was achieved at $600 \mathrm{mg} / \mathrm{L}$, which was $92.23 \%$. However, at a CSBT dose of $1000 \mathrm{mg} / \mathrm{L}$, the removal percentage decreased from $92.23 \%$ to $91.45 \%$. This decrement could be explained by the overlap of sorption sites that negatively affect the adsorption process. Despite the maximum removal percentage at $600 \mathrm{mg} / \mathrm{L}$, the adsorption capacity decreased with increasing CSBT dose. Therefore, the best dose of CSBT was chosen as $400 \mathrm{mg} / \mathrm{L}$.

3.5. Adsorption Isotherm. To investigate the reaction between CSBT and Cr (VI), the effect on the removal percentage and initial $\mathrm{Cr}$ (VI) concentration was studied. The result (Figure 8) has shown that at a higher initial Cr (VI) concentration, the adsorption capacity of CSBT is larger for a high driving force of high $\mathrm{Cr}$ (VI) concentration, which can overcome the resistance of $\mathrm{Cr}$ (VI) ions from the solution phase to the surface of the adsorbent [44], and the adsorbent can be exposed to more $\mathrm{Cr}$ (VI) ions, resulting in a higher adsorption capacity. The experimental data were analysed using the Langmuir, Freundlich, Temkin, and D-R isotherm models to further understand the interactions of $\mathrm{Cr}(\mathrm{VI})$ and the adsorbent, and the results are shown in Figures 9-12.

The parameters calculated are shown in Tables 6 and 7. The theoretical $Q_{m}$ at $298 \mathrm{~K}$ of the Langmuir isotherm is close to the experimental value of $137.43 \mathrm{mg} / \mathrm{g}$, and it is obvious that the Langmuir isotherm model gives better fit-

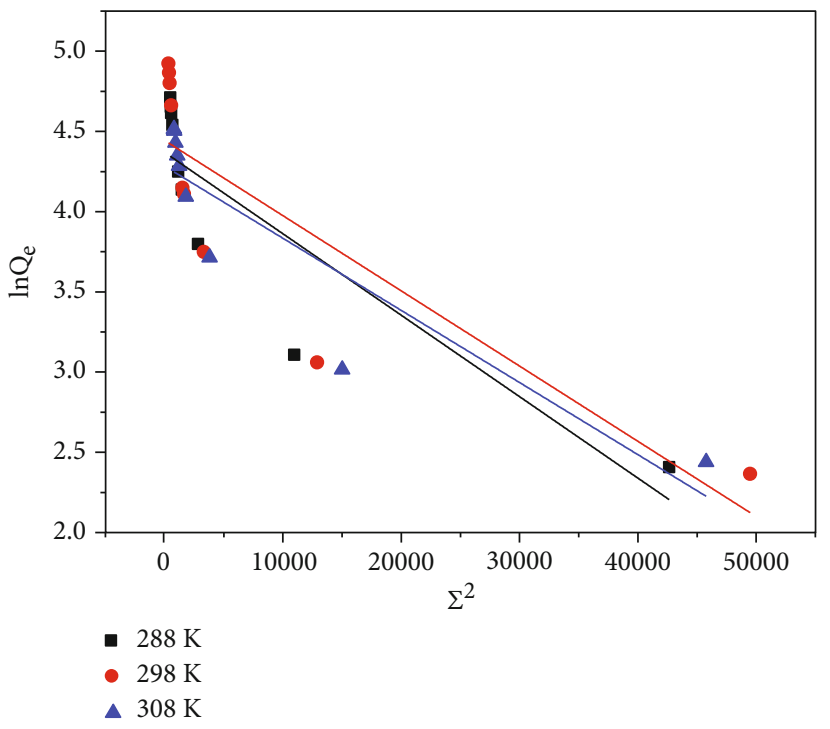

Figure 12: D-R isotherm for Cr (VI) removal on CSBT.

ting of the experimental data. This result described the adsorption behaviour of $\mathrm{Cr}$ (VI) onto the CSBT surface, and at each temperature, the $R^{2}$ value of the Langmuir isotherm was over 0.99, indicating that the adsorption was monolayer, and that the distribution of $\mathrm{Cr}$ (VI) ions between the solid and liquid phases was in equilibrium. Compared with other research materials, the maximum $\mathrm{Cr}$ (VI) adsorption capacity of CSBT is calculated to be $137.43 \mathrm{mg} / \mathrm{g}$, which is relatively better than most related adsorbents from the use environment and adsorption capacity [18, 19, 33]. Therefore, CSBT can stand out from current materials in a theoretical environment.

3.6. Adsorption Kinetics. Adsorption efficiency is of importance for the application of an adsorbent. Therefore, the effect of different stirring times on $\mathrm{Cr}$ (VI) removal was 
TABLE 6: Constants of Langmuir and Freundlich isotherm models for Cr (VI) removal of CSBT.

\begin{tabular}{lccccr}
\hline Temperature $(\mathrm{K})$ & $\begin{array}{c}Q_{m} \\
(\mathrm{mg} / \mathrm{g})\end{array}$ & $\begin{array}{c}K_{L} \\
(\mathrm{~L} / \mathrm{mg})\end{array}$ & $R^{2}$ & $\begin{array}{c}K_{F} \\
(\mathrm{mg} / \mathrm{g})\end{array}$ & $1 / n$ \\
\hline 288 & 110.49 & 0.1275 & 0.9976 & 24.55 & 0.2871 \\
298 & 133.85 & 0.0840 & 0.9937 & 19.80 & 0.8760 \\
308 & 90.14 & 0.1653 & 0.9965 & 21.90 & 0.3804 \\
\hline
\end{tabular}

TABle 7: Constants of Temkin and D-R isotherm models for Cr (VI) removal of CSBT.

\begin{tabular}{lccccrr}
\hline Temperature (K) & $A$ & $B$ & $R^{2}$ & $\begin{array}{c}Q_{m} \\
(\mathrm{mg} / \mathrm{g})\end{array}$ & $b$ & $R^{2}$ \\
\hline 288 & 27.66 & 14.4294 & 0.9570 & 4.37 & 5.0763 \\
298 & 17.08 & 20.1375 & 0.9679 & 4.44 & 4.6889 \\
308 & 26.14 & 11.6819 & 0.8906 & 4.28 & 4.4953 \\
\hline
\end{tabular}

TABle 8: Pseudofirst-order and pseudosecond-order kinetic model parameters for Cr (VI) adsorption of CSBT.

\begin{tabular}{lcccc}
\hline & Pseudofirst-order model & & \multicolumn{2}{c}{ Pseudosecond-order model } \\
$k_{1}\left(\mathrm{~min}^{-1}\right)$ & $Q_{e}(\mathrm{mg} / \mathrm{g})$ & $R^{2}$ & $k^{2}\left(\mathrm{mg}^{-1} \cdot \mathrm{min}^{-1}\right)$ & $\left.R^{2} / \mathrm{g}\right)$ \\
\hline 13.14587 & 21.4472 & 0.97052 & 1.10671 & 22.62311 \\
\hline
\end{tabular}

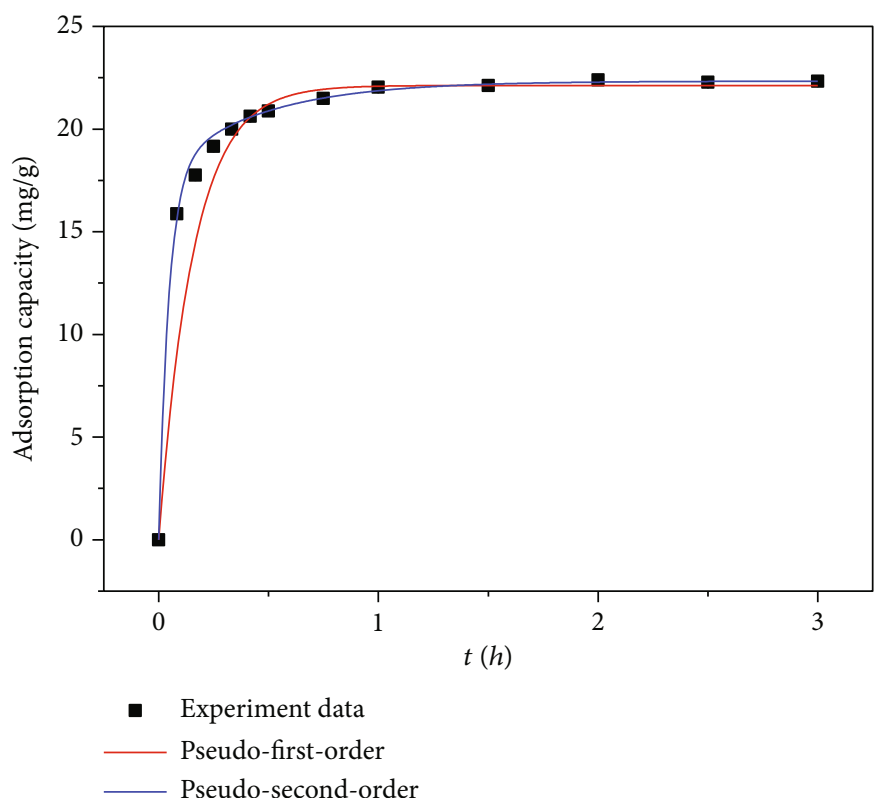

FIgURE 13: Adsorption kinetics for Cr (VI) removal on CSBT.

studied. During the initial 30 minutes, Cr (VI) was adsorbed quickly, and then the adsorption reached equilibrium at $1.5 \mathrm{~h}$. Such a fast adsorption process can be attributed to the fact that at the initial stage, adsorption mainly occurred on the adsorbent surface due to the strong electrostatic interaction between amino groups on CSBT and Cr (VI) in solutions, resulting in a fast initial adsorption rate [45]. After that, the adsorption process occurred internally because of the saturation of the sorption sites on the surface, and the adsorption slowed down until equilibrium.
To further understand the adsorption mechanism, experimental data were analysed using pseudofirst-order and pseudosecond-order kinetic models. As shown in Table 8 and Figure 13, the pseudosecond-order kinetic model has a higher correlation coefficient $\left(R^{2}=0.9978\right)$, and $Q_{e}(22.62 \mathrm{mg} / \mathrm{g})$ is closer to the experimental value $(22.39 \mathrm{mg} / \mathrm{g})$. In other words, the pseudosecond-order kinetic model is more suitable for describing the adsorption process of CSBT, and it demonstrated that the adsorption process is dependent on the reacting sites with $\mathrm{Cr}(\mathrm{VI})$. 


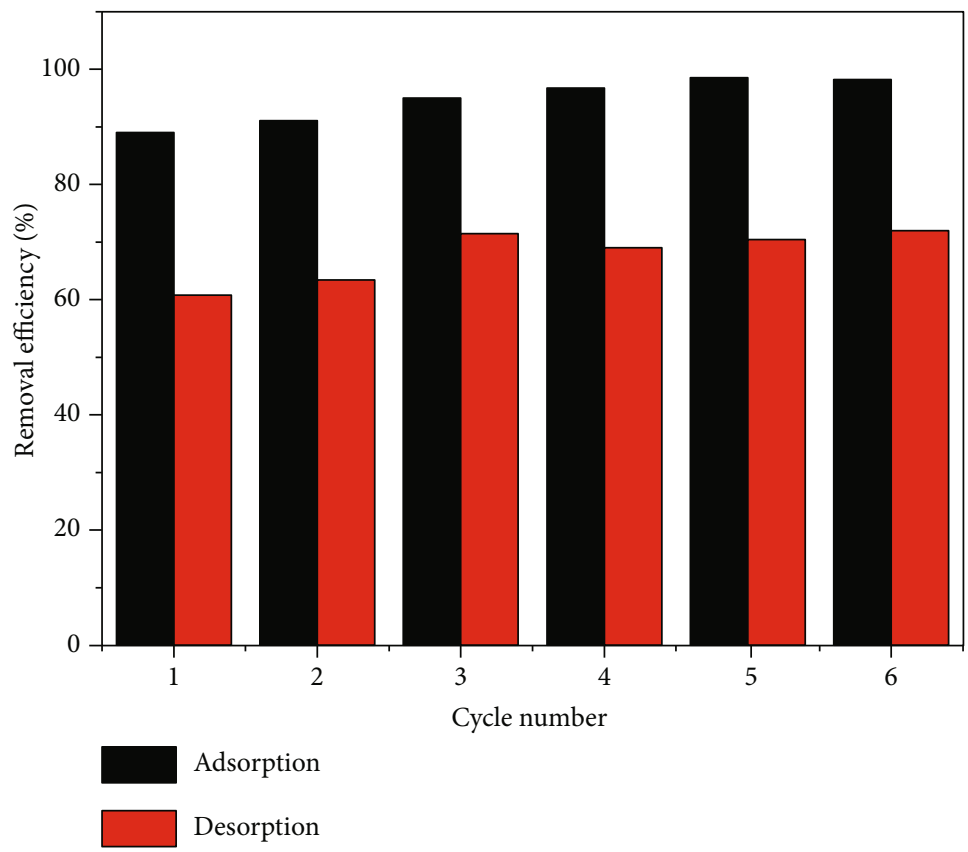

FIgURe 14: Desorption-regeneration cycles. (Absorbent dosaging, $400 \mathrm{mg} / \mathrm{L} ; \mathrm{pH}$ value, 3.0; initial concentration, $10 \mathrm{mg} / \mathrm{L}$; temperature, $298.15 \mathrm{~K}$; contact time, $90 \mathrm{~min}$; rpm, 180).
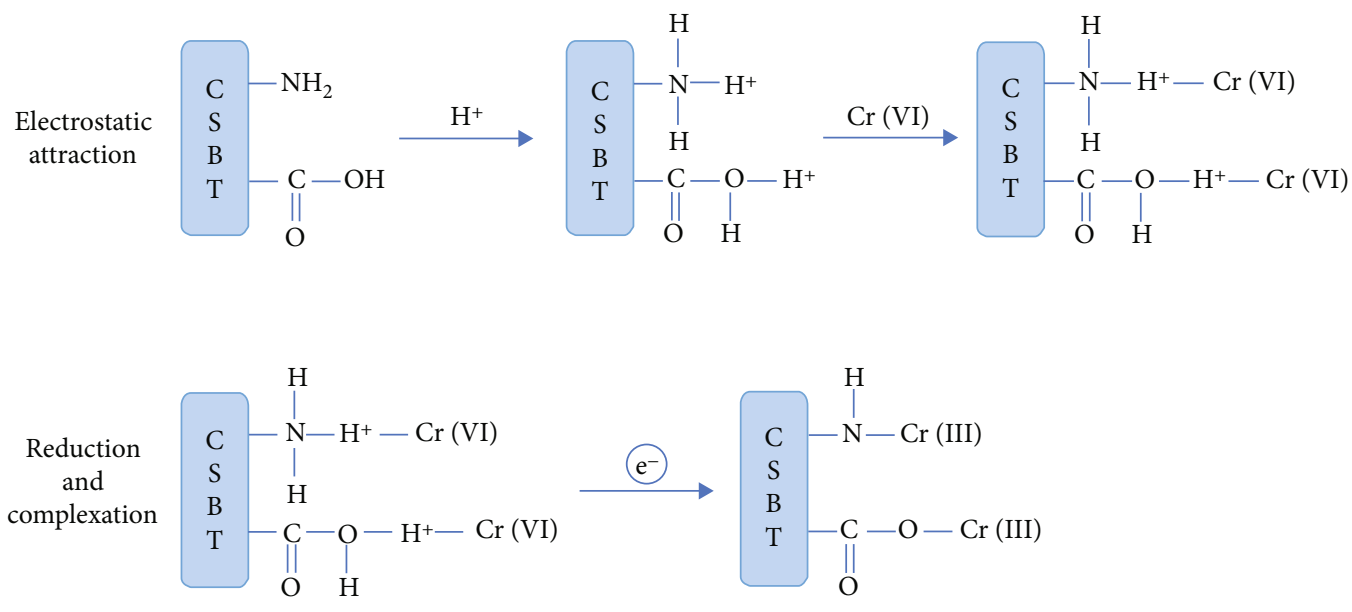

FIgURE 15: The adsorption mechanism of CSBT on Cr (VI).

3.7. Regeneration of CSBT. In practical applications, it can reduce the cost and recycle $\mathrm{Cr}$ (VI) resources if an adsorbent has better reusability. As discussed above, in alkaline solutions, the combination of hydroxyl groups and CSBT is more primary than $\mathrm{Cr}(\mathrm{VI})$; thus, alkaline solution can cause $\mathrm{Cr}$ (VI) ions to desorb. After-adsorption equilibrium, the adsorbent was transferred into $0.1 \mathrm{~mol} / \mathrm{L}$ sodium hydroxyl solution to desorb the $\mathrm{Cr}$ (VI) ions. Then, the adsorbent will be reused. After 5 cycles, the adsorption ability of CSBT to absorb Cr (VI) was not weakened but was stronger than last time (Figure 14). For the first time, $89 \%$ of $\mathrm{Cr}$ (VI) was adsorbed, and for the fifth time, $98 \%$ of $\mathrm{Cr}$ (VI) was adsorbed, and the removal percentage was increased by $9 \%$. The sixth adsorption rate decreased slightly, from $98.54 \%$ to $98.22 \%$. The desorption rate increases with increasing adsorption rate, and more than $60 \%$ of $\mathrm{Cr}$ (VI) can be recovered by elution with $\mathrm{NaOH}$. In summary, as a Cr (VI) adsorbent, CSBT can adsorb most Cr (VI) and has good reproducibility.

3.8. Adsorption Mechanism. According to FTIR and XRD, there are a large number of active functional groups (such as hydroxyl and amino groups) on the surface of CSBT, which can interact with $\mathrm{Cr}$ (VI) in ion exchange and precipitation. Due to the addition of iron-modified bentonite, a porous structure is formed on the surface of the chitosan hydrogel, and the adsorption performance is enhanced [27]. There are a large number of hydrogen ions in acidic solutions. The functional groups of CSBT can be combined with hydrogen ions, effectively reducing $\mathrm{Cr}$ (VI) in solution to $\mathrm{Cr}$ (III), which is less toxic and can be complexed on the surface of CSBT by precipitation and chelation 
[24-26]. The adsorption of $\mathrm{Cr}$ (VI) by CSBT is mainly completed by the following process: first, in an acidic environment, the amino groups $\left(-\mathrm{NH}_{2}\right)$ and carboxyl groups $(-\mathrm{COOH})$ on the surface of CSBT are easily protonated into $-\mathrm{NH}_{3}{ }^{+}$and $-\mathrm{COOH}^{+}$and electrostatically interact with the negatively charged $\mathrm{Cr}$ (VI) in the solution; then, combined with $\mathrm{H}^{+}$in the solution, $\mathrm{Cr}$ (VI) will be transformed into negatively charged $\mathrm{Cr}$ (III) acid radical ions, and part of the $\mathrm{Cr}$ (III) will interact with the CSBT surface. The functional groups undergo chelation and precipitation (Figure 15). In summary, the adsorption of Cr (VI) by CSBT is a complex and changeable process that mainly involves electrostatic interactions, reduction, and coprecipitation.

\section{Conclusions}

The composite material CSBT was successfully prepared by the reaction of chitosan and pillared bentonite. The layered structure of bentonite was not destroyed after composition; instead, amino groups on chitosan were connected to the pillared bentonite by hydrogen bonds. During the adsorption process, the amino groups were protonated and combined with anionic hexavalent chromium for the purpose of $\mathrm{Cr}$ (VI) removal. The composites have an efficient effect on $\mathrm{Cr}$ (VI) removal at a wide range of temperatures and adsorbent doses. However, Cr (VI) removal has been limited by the $\mathrm{pH}$ value of the solutions. The optimal factors for $\mathrm{Cr}$ (VI) removal by response surface methodology were estimated to be $298 \mathrm{~K}$ of temperature, $\mathrm{pH}=3$, and $400 \mathrm{mg} / \mathrm{L}$ of adsorbent dose, which can remove $87.61 \%$ of $\mathrm{Cr}$ (VI) in potassium dichromate solution. The Langmuir isotherm model and the pseudosecond-order kinetic model fit the experimental data best. The maximum adsorption capacity predicted for CSBT at $298 \mathrm{~K}$ is $133.85 \mathrm{mg} / \mathrm{g}$, which is close to the experimental value of $137.43 \mathrm{mg} / \mathrm{g}$. CSBT can be reused and maintained a high removal efficiency after six cycles.

\section{Data Availability}

The data produced or investigated during this work are involved in this submitted article.

\section{Conflicts of Interest}

The authors declare that there is no conflict of interest regarding the publication of this article.

\section{Acknowledgments}

This research was supported by the National Natural Science Foundation of China (grant number U2006212).

\section{References}

[1] A. Debnath, A. Bera, K. K. Chattopadhyay, and B. Saha, "Facile additive-free synthesis of hematite nanoparticles for enhanced adsorption of hexavalent chromium from aqueous media: kinetic, isotherm, and thermodynamic study," Inorganic and Nano-Metal Chemistry, vol. 47, no. 12, pp. 1605-1613, 2017.
[2] K. Sahin, M. Onderci, M. Tuzcu et al., "Effect of chromium on carbohydrate and lipid metabolism in a rat model of type 2 diabetes mellitus: the fat-fed, streptozotocin-treated rat," Metabolism Clinical and Experimental, vol. 56, no. 9, pp. 1233-1240, 2007.

[3] T.-C. Chou, P.-C. Wang, J.-D. Wu, and S.-C. Sheu, "Chromium-induced skin damage among Taiwanese cement workers," Toxicology and Industrial Health, vol. 32, no. 10, pp. 1745-1751, 2016.

[4] B. Gammelgaard, A. Fullerton, C. Avnstorp, and T. Menné, "Permeation of chromium salts through human skin in vitro," Contact Dermatitis, vol. 27, no. 5, pp. 302-310, 1992.

[5] K. L. Bhowmik, A. Debnath, R. K. Nath, and B. Saha, "Synthesis of $\mathrm{MnFe} 2 \mathrm{O} 4$ and $\mathrm{Mn} 3 \mathrm{O} 4$ magnetic nano-composites with enhanced properties for adsorption of $\mathrm{Cr}(\mathrm{VI})$ : artificial neural network modeling," Water Science and Technology : A Journal of the International Association on Water Pollution Research, vol. 76, no. 12, pp. 3368-3378, 2017.

[6] K. Yatera, Y. Morimoto, S. Ueno et al., "Cancer risks of hexavalent chromium in the respiratory tract," Journal of Uoeh, vol. 40, no. 2, pp. 157-172, 2018.

[7] A. K. Mishra and B. Mohanty, "Acute toxicity impacts of hexavalent chromium on behavior and histopathology of gill, kidney and liver of the freshwater fish, _Channa punctatus_ (Bloch)," Environmental Toxicology and Pharmacology, vol. 26, no. 2, pp. 136-141, 2008.

[8] J. B. Dima, C. Sequeiros, and N. E. Zaritzky, "Hexavalent chromium removal in contaminated water using reticulated chitosan micro/nanoparticles from seafood processing wastes," Chemosphere, vol. 141, pp. 100-111, 2015.

[9] W. Qi, Y. Zhao, X. Zheng, M. Ji, and Z. Zhang, "Adsorption behavior and mechanism of $\mathrm{Cr}(\mathrm{VI})$ using Sakura waste from aqueous solution," Applied Surface Science, vol. 360, pp. 470476, 2016.

[10] H. P. Singh, P. Mahajan, S. Kaur, D. R. Batish, and R. K. Kohli, "Chromium toxicity and tolerance in plants," Environmental Chemistry Letters, vol. 11, no. 3, pp. 229-254, 2013.

[11] A. Nam, U. S. Choi, S. T. Yun, J. W. Choi, J. A. Park, and S.-H. Lee, "Evaluation of amine-functionalized acrylic ion exchange fiber for chromium(VI) removal using flow-through experiments modeling and real wastewater," Journal of Industrial and Engineering Chemistry, vol. 66, pp. 187-195, 2018.

[12] K. Sangeetha, P. Angelin Vinodhini, P. N. Sudha, A. Alsharani Faleh, and A. Sukumaran, "Novel chitosan based thin sheet nanofiltration membrane for rejection of heavy metal chromium," International Journal of Biological Macromolecules, vol. 132, pp. 939-953, 2019.

[13] H. Sarahney, X. Mao, and A. N. Alshawabkeh, "The role of iron anode oxidation on transformation of chromium by electrolysis," Electrochimica Acta, vol. 86, pp. 96-101, 2012.

[14] K. Yan, Z. Liu, Z. Li, R. Yue, F. Guo, and X. Zhifeng, "Selective separation of chromium from sulphuric acid leaching solutions of mixed electroplating sludge using phosphate precipitation," Hydrometallurgy, vol. 186, pp. 42-49, 2019.

[15] B. Zhang, Z. Wang, J. Shi, and H. Dong, "Sulfur-based mixotrophic bio-reduction for efficient removal of chromium (VI) in groundwater," Geochimica et Cosmochimica Acta, vol. 268, pp. 296-309, 2020.

[16] P. Miretzky and A. Fernandez Cirelli, "Cr(VI) and $\mathrm{Cr}(\mathrm{III})$ removal from aqueous solution by raw and modified lignocellulosic materials: a review," Journal of Hazardous Materials, vol. 180 , no. 1-3, pp. 1-19, 2010. 
[17] L. Ren, J. Xu, Y. Zhang, J. Zhou, D. Chen, and Z. Chang, "Preparation and characterization of porous chitosan microspheres and adsorption performance for hexavalent chromium," International Journal of Biological Macromolecules, vol. 135, pp. 898-906, 2019.

[18] J. Tan, Y. Song, X. Huang, and L. Zhou, "Facile functionalization of natural peach gum polysaccharide with multiple amine groups for highly efficient removal of toxic hexavalent chromium (Cr(VI)) ions from water," ACS Omega, vol. 3, no. 12, pp. 17309-17318, 2018.

[19] J. Valentín-Reyes, R. B. García-Reyes, A. García-González, E. Soto-Regalado, and F. Cerino-Córdova, "Adsorption mechanisms of hexavalent chromium from aqueous solutions on modified activated carbons," Journal of Environmental Management, vol. 236, pp. 815-822, 2019.

[20] L. Wang and A. Wang, "Adsorption characteristics of Congo Red onto the chitosan/montmorillonite nanocomposite," Journal of Hazardous Materials, vol. 147, no. 3, pp. 979-985, 2007.

[21] J. Desbrières and E. Guibal, "Chitosan for wastewater treatment," Polymer International, vol. 67, no. 1, pp. 7-14, 2018.

[22] P. M. Pakdel and S. J. Peighambardoust, "Review on recent progress in chitosan-based hydrogels for wastewater treatment application," Carbohydrate Polymers, vol. 201, pp. 264-279, 2018.

[23] Q. Liu, B. Yang, L. Zhang, and R. Huang, "Adsorption of an anionic azo dye by cross-linked chitosan/bentonite composite," International Journal of Biological Macromolecules, vol. 72, pp. 1129-1135, 2015.

[24] D. Komoto, T. Furuike, and H. Tamura, "Preparation of polyelectrolyte complex gel of sodium alginate with chitosan using basic solution of chitosan," International Journal of Biological Macromolecules, vol. 126, pp. 54-59, 2019.

[25] R. Li, W. Liang, M. Li et al., "Removal of Cd(II) and Cr(VI) ions by highly cross-linked Thiocarbohydrazide- chitosan gel," International Journal of Biological Macromolecules, vol. 104, Part A, pp. 1072-1081, 2017.

[26] H. Y. Zhu, Y. Q. Fu, R. Jiang, J. Yao, L. Xiao, and G. M. Zeng, "Novel magnetic chitosan/poly(vinyl alcohol) hydrogel beads: preparation, characterization and application for adsorption of dye from aqueous solution," Bioresource Technology, vol. 105, pp. 24-30, 2012.

[27] B. Huang, M. Liu, and C. Zhou, "Chitosan composite hydrogels reinforced with natural clay nanotubes," Carbohydrate Polymers, vol. 175, pp. 689-698, 2017.

[28] F. A. R. Pereira, K. S. Sousa, G. R. S. Cavalcanti, M. G. Fonseca, A. G. de Souza, and A. P. M. Alves, "Chitosan-montmorillonite biocomposite as an adsorbent for copper (II) cations from aqueous solutions," International Journal of Biological Macromolecules, vol. 61, pp. 471-478, 2013.

[29] Y. Zhang, B.-T. Zhang, Y. Teng, J. Zhao, and X. Sun, "Heterogeneous activation of persulfate by carbon nanofiber supported $\mathrm{Fe}_{3} \mathrm{O}_{4} @$ carbon composites for efficient ibuprofen degradation," Journal of Hazardous Materials, vol. 401, p. 123428, 2021.

[30] H. Cheng, Q. Zhu, A. Wang, M. Weng, and Z. Xing, "Composite of chitosan and bentonite cladding Fe-Al bimetal: Effective removal of nitrate and by-products from wastewater," Environmental Research, vol. 184, p. 109336, 2020.

[31] G. Conzatti, D. Faucon, M. Castel, F. Ayadi, S. Cavalie, and A. Tourrette, "Alginate/chitosan polyelectrolyte complexes: a comparative study of the influence of the drying step on physicochemical properties," Carbohydrate Polymers, vol. 172, pp. 142-151, 2017.
[32] N. Sereni, A. Enache, G. Sudre et al., "Dynamic structuration of physical chitosan hydrogels," Langmuir, vol. 33, no. 44, pp. 12697-12707, 2017.

[33] P. Yu, H.-Q. Wang, R.-Y. Bao et al., "Self-assembled spongelike chitosan/reduced graphene oxide/montmorillonite composite hydrogels without cross-linking of chitosan for effective Cr(VI) sorption," ACS Sustainable Chemistry \& Engineering, vol. 5, no. 2, pp. 1557-1566, 2017.

[34] K. Wang, H. Ma, S. Pu et al., "Hybrid porous magnetic bentonite-chitosan beads for selective removal of radioactive cesium in water," Journal of Hazardous Materials, vol. 362, pp. 160-169, 2019.

[35] L. Li, Y. Li, L. Cao, and C. Yang, "Enhanced chromium (VI) adsorption using nanosized chitosan fibers tailored by electrospinning," Carbohydrate Polymers, vol. 125, pp. 206-213, 2015.

[36] L. Jin and R. Bai, "Mechanisms of lead adsorption on chitosan/PVA hydrogel beads," Langmuir, vol. 18, no. 25, pp. 9765-9770, 2002.

[37] T. Ravi and S. Anuradha Jabasingh, "Preparation and characterization of higher degree-deacetylated chitosan-coated magnetic adsorbent for the removal of chromium(VI) from its aqueous mixture," Journal of Applied Polymer Science, vol. 135, no. 9, 2018.

[38] M. Bhowmik, K. Deb, A. Debnath, and B. Saha, "Mixed phase $\mathrm{Fe} 2 \mathrm{O} 3 / \mathrm{Mn} 3 \mathrm{O} 4$ magnetic nanocomposite for enhanced adsorption of methyl orange dye: neural network modeling and response surface methodology optimization," Applied Organometallic Chemistry, vol. 32, no. 3, article e4186, 2018.

[39] N. H. Singh, K. Kezo, A. Debnath, and B. Saha, "Enhanced adsorption performance of a novel $\mathrm{Fe}-\mathrm{Mn}-\mathrm{Zr}$ metal oxide nanocomposite adsorbent for anionic dyes from binary dye mix: response surface optimization and neural network modeling," Applied Organometallic Chemistry, vol. 32, no. 3, article e4165, 2018.

[40] Z. Yu, X. Zhang, and Y. Huang, "Magnetic chitosan-iron(III) hydrogel as a fast and reusable adsorbent for chromium(VI) removal," Industrial \& Engineering Chemistry Research, vol. 52, no. 34, pp. 11956-11966, 2013.

[41] E. Guibal, C. Milot, and J. M. Tobin, "Metal-anion sorption by chitosan beads: equilibrium and kinetic studies," Industrial \& Engineering Chemistry Research, vol. 37, no. 4, pp. 14541463, 1998.

[42] M. J. V. Thamilarasi, P. Anilkumar, C. Theivarasu, and M. V. Sureshkumar, "Removal of vanadium from wastewater using surface-modified lignocellulosic material," Environmental Science and Pollution Research, vol. 25, no. 26, pp. 26182-26191, 2018.

[43] S. Chen, W. Shen, F. Yu, and H. Wang, "Kinetic and thermodynamic studies of adsorption of $\mathrm{Cu} 2+$ and $\mathrm{Pb} 2+$ onto amidoximated bacterial cellulose," Polymer Bulletin, vol. 63, no. 2, pp. 283-297, 2009.

[44] J. Zhang, Q. Zhou, and O. Lailiang, "Kinetic, isotherm, and thermodynamic studies of the adsorption of methyl orange from aqueous solution by chitosan/alumina composite," Journal of Chemical \& Engineering Data, vol. 57, no. 2, pp. 412419, 2012.

[45] S. Pu, Y. Hou, C. Yan et al., "In situ coprecipitation formed highly water-dispersible magnetic chitosan nanopowder for removal of heavy metals and its adsorption mechanism," ACS Sustainable Chemistry \& Engineering, vol. 6, no. 12, pp. 16754-16765, 2018. 